\title{
Efeitos sociais derivados da implementação de políticas públicas: uma análise do Programa Bolsa-Família
}

\author{
Marisa da Conceição Teixeira' \\ Breynner Ricardo de Oliveira²
}

\begin{abstract}
Resumo
A partir da condicionalidade educacional do Programa Bolsa Família (PBF), o artigo analisa os efeitos da implementação na interação cotidiana das burocratas de nível de rua com beneficiárias. Os dados derivam de entrevistas realizadas com sete implementadoras que atuam em uma escola municipal e um Centro de Referência de Assistência Social (CRAS) localizados em um território com alta vulnerabilidade social em Ouro Preto, Minas Gerais. As entrevistas revelam os efeitos perversos e seus entrelaçamentos, associados à interação cotidiana entre implementadoras e beneficiárias: preconceitos; estigmas sobre as famílias; reforço de repertórios morais; classificações; controles sociais e julgamentos.

\section{Palavras-chave}

Efeitos da implementação. Programa Bolsa-Família. Desigualdades sociais. Reprodução de desigualdades
\end{abstract}

Social effects derived from the implementation of public policies: an analysis of the Bolsa-Família Program

\begin{abstract}
Based on the educational conditionality of the Bolsa Familia Program (BFP), the article analyzes the effects of the implementation on the daily interaction of street level bureaucrats with beneficiaries. Data are derived from interviews conducted with seven implementers who work in a municipal school and a Social Assistance Reference Center (CRAS) located in a territory with high social vulnerability in Ouro Preto, Minas Gerais. The interviews reveal the perverse effects associated with the daily interaction between implementers and beneficiaries: prejudices; stigmas on families; reinforcement of moral repertoires; ratings; social controls and judgments.
\end{abstract}

\section{Keywords}

Effects of implementation. Bolsa Família Program. Social Inequalities. Reproduction of Inequalities

Artigo enviado em julho de 2021

Artigo aprovado em setembro de 2021 


\section{Introdução}

O artigo analisa os efeitos sociais da implementação do Programa Bolsa Família (PBF) a partir da condicionalidade educacional e seus entrelaçamentos, associados à reprodução das desigualdades. Busca-se investigar as classificações estigmatizantes, os controles sociais e os julgamentos morais que se desenvolvem em torno da figura dos beneficiários, o que pode, segundo Oliveira e Peixoto (2019), acentuar as assimetrias sociais que, pretensamente, tais políticas querem mitigar.

A discussão parte dos estudos de Lispky (1980) sobre implementação de políticas públicas, um campo que, desde os anos 1970, vem desenvolvendo uma vertente de análise sobre a atuação do Estado e sobre as interações entre os agentes encarregados de prover serviços públicos na ponta e os cidadãos a quem as políticas se destinam. De acordo com esse autor, tais agentes que atuam na ponta, nos territórios e nos equipamentos públicos que atendem diretamente os cidadãos são os "burocratas de nível da rua" - servidores públicos que interagem diretamente com os cidadãos no cumprimento de suas tarefas e que têm considerável discricionariedade na execução cotidiana de seu trabalho. Segundo o autor, esses trabalhadores de nível da rua podem promover modificações no curso das ações e nos resultados da política.

A análise se deu no município de Ouro Preto (Minas Gerais), onde foram selecionados dois equipamentos públicos: uma escola municipal e um Centro de Referência de Assistência Social (CRAS) situados no mesmo território em situação de vulnerabilidade. Os dados advêm de sete entrevistas semiestruturadas com uma cadastradora do PBF, uma assistente social e cinco profissionais da educação: uma diretora, uma pedagoga, uma secretária escolar e duas professoras ${ }^{3}$. As entrevistas abrangeram duas dimensões: (1) Percepções e práticas das implementadoras e (2) Cotidiano de trabalho. As questões do roteiro contemplaram os efeitos da implementação, entrelaçados entre positivos e negativos. As entrevistas buscaram compreender como os 
implementadores percebem os meios pelos quais a população mais pobre e alvo do PBF acessa seus direitos; a visão assistencialista, de ajuda ou de julgamentos sobre os benefícios e serviços do Estado; as estratégias adotadas pelos agentes da ponta; como lidam e conduzem situações adversas e como esses efeitos estão entrelaçados.

Criado em 2003, no início do governo de Luiz Inácio Lula da Silva, o PBF unificou os programas de transferência de renda já existentes (Bolsa-Escola, Bolsa Alimentação e o Auxílio Gás, instituídos no governo Fernando Henrique Cardoso) e o Cartão Alimentação, criado no início do Governo Lula. Posteriormente, em 2006, também incorporou o Programa de Erradicação do Trabalho Infantil (PETI) (SILVA, YAZBEK, DI GIOVANNI, 2012; COHN, 2012). Mantido por Dilma Rousseff e por Jair Bolsonaro, é o programa social com maior cobertura no país, atendendo cerca de 14,6 milhões de famílias, conforme dados do Ministério da Cidadania (BRASIL, 2021).

O programa é uma política de transferência de renda com condicionalidades. Foi idealizado com o objetivo de contribuir para a inclusão social de milhões de famílias brasileiras em situação de pobreza e para viabilizar o atendimento dessa população a serviços públicos de saúde, educação e assistência social e, assim, contribuir para o rompimento do ciclo intergeracional de pobreza (BRASIL, 2004).

Conforme Oliveira e Daroit (2020), embora o PBF seja uma política social, a exigência da frequência escolar vincula o social à política educacional, produzindo um movimento fluido entre esses campos. Segundo esses autores, o PBF conforma uma rede que articula outras políticas, mobilizando beneficiários, equipamentos públicos, implementadores, pessoas, rotinas, processos, recursos e territórios. Em outras palavras, a contrapartida educacional aciona uma complexa logística de provisão de bens e serviços sociais visando o rompimento do ciclo intergeracional de reprodução da pobreza.

A respeito das análises de políticas de combate à pobreza, Marins (2017) esclarece que as pesquisas no Brasil ainda dão pouca impor- 
tância aos discursos dos diferentes agentes que produzem as representações coletivas, as classificações sociais e morais e as distinções simbólicas que agrupam pessoas e comportamentos. Para além dos critérios do PBF, os julgamentos categorizam pessoas como moralmente merecedoras, ou não, de receber o benefício. A política pública passa pelas normas estabelecidas pelo Estado, mas é necessário avaliar a defasagem entre essas e as práticas cotidianas, uma vez que os burocratas de nível de rua também estabelecem critérios e podem, ou não, aplicar essas normas institucionais.

Nessa direção, as pesquisas no campo da implementação reforçam a tese de que leis e decisões políticas não são mecanicamente executadas, tal como planejadas e concebidas. Pelo contrário, ao tratar dos efeitos sociais da implementação, Pires (2019) mostra que leis e programas colocados em ação requerem o envolvimento de múltiplos atores e mobilizam procedimentos e interações que não são neutros e, portanto, influenciam a forma como a política é produzida, afetando seus resultados.

Ao tratar dessas questões, o autor afırma que as dinâmicas de implementação de políticas podem produzir efeitos negativos, inesperados e colaterais, reproduzindo desigualdades - exatamente o que se pretende reduzir. Pires (2019) analisa esses efeitos a partir de duas dimensões: (1) a que chama atenção para o desenho institucional e a tentativa de aprimorar o controle e o desempenho das políticas públicas e (2) a que tem o olhar voltado para os agentes implementadores, suas ações, comportamentos e interações com os usuários a quem as políticas se destinam.

A discussão empreendida nesse artigo concentra-se nos efeitos derivados da segunda dimensão: estigmas, julgamentos, controles morais e preconceitos. Segundo Goffman (1982), tais valorações emergem quando o indivíduo deixa de ser considerado como criatura comum e total e passa a ser reduzido a uma "pessoa estragada e diminuída". Ao analisar preconceitos, estigmas, classificações por merecimento e jul- 
gamentos morais por parte dos trabalhadores sociais e da educação vinculados ao PBF em dois equipamentos públicos de Ouro Preto, evidenciam-se, portanto, os efeitos sociais negativos que são fruto dos processos de interação entre tais sujeitos e os cidadãos, ao longo da implementação no nível local.

Para tanto, o artigo está dividido em duas seções, além dessa introdução e das considerações finais. Na primeira seção, discute-se os efeitos sociais da implementação que podem reproduzir desigualdades. A segunda seção analisa os dados obtidos nas entrevistas, discutindo as percepções e práticas estigmatizantes das burocratas de nível de rua em relação às mulheres atendidas pelo PBF.

\section{Implementação de políticas públicas e a reprodução de desigualdades: a produção de efeitos sociais negativos}

Segundo Pires (2019), as políticas sociais devem mitigar o sofrimento gerado pela exclusão social e combater desigualdades. Contudo, na trajetória das políticas e dos serviços públicos, no momento em que os cidadãos se vinculam a essas ações, os contextos de implementação e as interações na linha de frente do serviço público podem reforçar a vulnerabilidade social, reproduzindo práticas de exclusão e desigualdades.

Para o autor, as pesquisas sobre políticas públicas mais hegemônicas tendem a valorizar a definição de problemas e agendas no debate público, as tomadas de decisão relativas à formulação de políticas, a explicação das condições de mudanças das políticas públicas e os discursos e estratégias dos representantes políticos e membros do alto escalão da burocracia pública. Contudo, desde os anos 1970, vem sendo desenvolvida uma nova perspectiva de análise voltada para a implementação de políticas e programas, evidenciando o cotidiano das ações públicas, especialmente nos territórios, a partir da atuação dos agentes que atuam nos equipamentos públicos, atendendo os cidadãos.

É nesse campo que a teoria desenvolvida por Lipsky (1980) sobre a "burocracia do nível da rua" se inscreve. O autor analisa as decisões 
tomadas pelos agentes da linha de frente em relação aos cidadãos, quando estão executando as políticas que lhes são destinadas. Trata-se, portanto, de compreender e analisar o cotidiano de trabalho de professores, assistentes sociais, médicos, enfermeiras, policiais, agentes comunitários e outros atores que representam o Estado no nível local, exercendo sua função em equipamentos públicos voltados ao atendimento e provisão de bens e serviços à população - escolas, centros de saúde, delegacias, creches, centros de apoio, dentre outros.

Nessa perspectiva teórica, Oliveira (2014) afirma que certas situações não previstas na formulação só podem ser resolvidas no momento em que ocorrem e essa decisão se dá por meio da discricionariedade dos burocratas de nível de rua. Para o autor, como são os próprios agentes que se relacionam diretamente com os cidadãos e que possuem o verdadeiro conhecimento sobre a situação, não se pode exigir deles a tomada de uma decisão que seja baseada numa solução definida abstratamente ou que sigam unicamente regras prescritas institucionalmente. Segundo essa teoria, a discricionariedade na prestação de serviços torna os atores da ponta essenciais na implementação de políticas públicas. Lipsky (1980) afırma que os burocratas de nível da rua são os verdadeiros formuladores de política.

A discricionariedade dos agentes de linha de frente pode ser positiva ou negativa. Para Winter (2013), embora tentem fazer o melhor possível, esses agentes experimentam uma lacuna entre as demandas deles exigida e sua intensa carga de trabalho. Nesse sentido, podem: racionar serviços; atribuir prioridade a suas tarefas em detrimento de tarefas complicadas; aplicar poucas classificações padronizadas para agrupar clientes; podem ser parciais; podem favorecer certos usuários da política e negligenciar outros e podem construir percepções sobre os usuários e sobre suas intenções, modificando as práticas e estratégias que adotam para realizar seu trabalho.

Sobre essas questões, Oliveira (2014) esclarece que a política muda à medida que é executada e que seu sucesso ou fracasso depende 
também da atuação dos agentes envolvidos diretamente nessa etapa. Para Pires (2019), a discricionariedade dos burocratas que atuam na linha de frente é mais decisiva quanto mais precárias forem as condições de trabalho, mais escassos forem os recursos, maior o volume de demandas, maior distanciamento das esferas de formulação central, maior complexidade das regras e imediaticidade dos encontros face a face com os usuários para desempenhar seu trabalho. Assim, a distorção dos objetivos iniciais das políticas públicas é tanto mais provável quanto maior a ação discricionária.

Lipsky (1980) e Maynard-Moody e Musheno (2003) discorrem a respeito da implementação de políticas públicas desenvolvidas por trabalhadores em escolas, tribunais e órgãos de assistência social, entre outros serviços públicos. Por fazerem a interface entre o Estado e os cidadãos, com considerável discrição em suas ações, esses agentes ocupam posição influente na execução de políticas públicas. Não apenas executam, mas também moldam ativamente os resultados das políticas, interpretando regras e alocando recursos escassos. Assim, tais agentes produzem políticas públicas tal como os cidadãos a experimentam. Segundo Meyers e Vorsanger (2013), as decisões e ações no nível da rua são orientadas mais por crenças e normas sobre o que é justo e menos por regras, treinamentos ou procedimentos. A dimensão subjetiva e pessoal do agente executor tem centralidade nas ações públicas.

É nesse sentido que a implementação produz efeitos. Ao analisar essas dinâmicas, Pires (2019) elenca duas dimensões que estruturam a discussão sobre os efeitos derivados desses processos, conforme disposto na figura 1. A primeira concentra-se nos arranjos e instrumentos de implementação, que apresentam mecanismos e riscos geradores de efeitos materiais e simbólicos da implementação. A segunda dimensão, por sua vez, concentra-se nas práticas de implementação e interações nas linhas de frente do serviço público que podem produzir efeitos não esperados, como estigmas e preconceitos. Essa é a vertente que será analisada neste artigo. 
Figura 1: Mecanismos e riscos de reprodução de desigualdade em processos de implementação

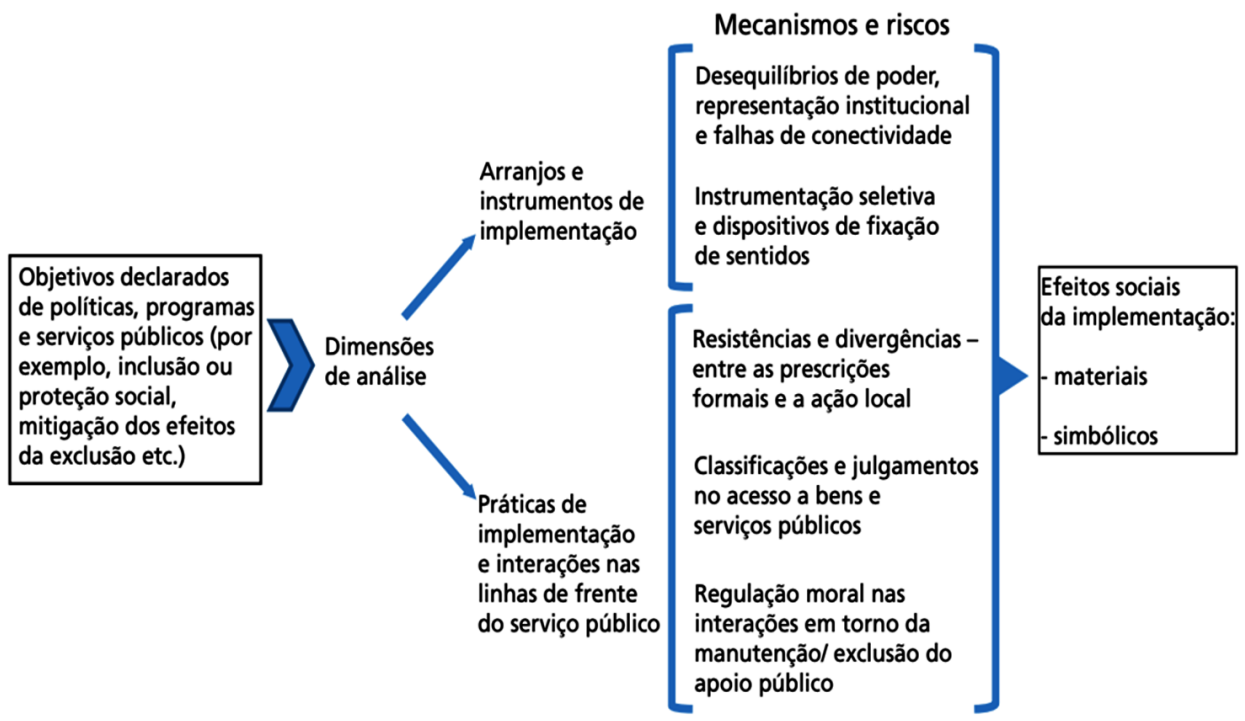

Fonte: reproduzido de Pires (2019).

Pelo lado das incertezas da concretização dos objetivos formais, o autor esclarece que devem ser analisadas as falhas e insuficiências ocorridas na dinâmica da implementação que correspondam aos resultados frustrados. Por outro lado, para os efeitos não pretendidos, considera-se a identificação dos processos e mecanismos deflagradores de efeitos colaterais, que acontecem fora do alvo da intervenção, e os efeitos perversos, incidentes sobre o alvo, mas em sentido contrário aos pretendidos pela norma. Entre os efeitos não pretendidos, o autor destaca o efeito social da implementação.

Esse efeito refere-se ao conjunto de repercussões sobre a posição, a trajetória e a identificação social de um sujeito que está inserido em um programa ou serviço do governo. É um efeito que opera sobre as redes de posições na qual esse sujeito está inserido e pode afastá-lo ou incorporá-lo nessa rede. Assim, Pires (2019) destaca que as relações estabelecidas com instituições e agentes públicos são decisivas na constituição de um sentido de lugar social para os sujeitos, visto 
que essas relações possuem desdobramentos tanto materiais quanto simbólicos para uma leitura que os usuários da política fazem sobre seu lugar no espaço social.

De acordo com Ayuero (2011), os encontros entre os agentes públicos e os usuários desses serviços envolvem vergonha, humilhação, acolhimento, demora, exercício de direitos, dentre outras experiências cotidianas, permeadas por crenças, valores e percepções. Segundo Dubois (2020), o cotidiano dos agentes implementadores é marcado por incertezas e dilemas sobre como proceder em cada situação. Consequentemente, as experiências adquiridas ao longo do tempo fazem com que esses burocratas desenvolvam práticas de atuação para reduzir essas incertezas.

Maynard-Moody e Musheno (2003) destacam que umas das estratégias mais comuns são os sistemas de classificação que lhes permitem rapidamente diferenciar os beneficiários das políticas à sua frente e dar as respostas cabíveis às demandas. Esses sistemas de classificação mesclam categorias formais fornecidas pelas normas das políticas públicas com categorias de julgamentos morais, baseados em valores, estereótipos e preconcepções dominantes de uma sociedade.

Segundo esses autores, a aplicação de regras e procedimentos formais da política/serviço público passa a ser mediada por julgamentos normativos e classificações identitárias que os agentes de ponta constroem sobre o público atendido. Essas classificações e esses julgamentos, por sua vez, são portadores de preconcepções sobre os usuários, permitindo situá-los como mais ou menos merecedores dos benefícios oferecidos pelo Estado e dos esforços empreendidos pelos agentes em favor de suas demandas.

Nessa direção, Pires (2019) afirma que um dos mecanismos de produção de riscos de reprodução de desigualdades na implementação de políticas diz respeito à regulação moral das condutas dos beneficiários da política pública, associados às interações que ocorrem em torno da manutenção do apoio, a partir do momento em que o sujeito passou a se reconhecer e a ser reconhecido como beneficiário. 
As sociedades estabelecem meios para categorizar as pessoas, imputando a elas atributos considerados comuns e naturais para os membros dessa categoria. Para Goffman (1982), os ambientes sociais estabelecem as categorias de pessoas que neles serão encontradas e as relações sociais nesses ambientes nos permitem prever a identidade social de uma pessoa estranha que nos é apresentada. Assim, essas preconcepções transformam-se em expectativas normativas: o tempo todo fazemos exigências sobre como o indivíduo à nossa frente deveria ser. Essa caracterização é chamada por Goffman (1982) de identidade social virtual e a categoria e os atributos que o indivíduo na realidade prova possuir são chamados pelo autor de identidade social real.

Goffman (1982) apresenta três tipos de estigmas diferentes: as abominações do corpo, deformidades físicas; as culpas de caráter individual, percebidas como vontade fraca, crenças falsas e rígidas, desonestidade, inferidas a partir de relatos de distúrbio mental, alcoolismo, prisão, vício, desemprego, entre outros; e os estigmas tribais de raça, nação e religião, que podem ser transmitidos por gerações.

É possível compreender que os estigmas são atributos depreciativos estabelecidos mais pelas interações entre os indivíduos que pelos atributos em si. Para Coffman (1982) é importante analisar a questão dos 'contatos mistos', momentos em que os estigmatizados estão na mesma situação social que os "normais".

Ao prever tais situações de contato, os "normais" e os estigmatizados tendem a esquematizar a vida de modo a evitar as interações. Isso pode ter maiores consequências para os estigmatizados, pois terão uma maior esquematização e a pessoa que se isola pode tornar-se desconfiada, deprimida, ansioso, hostil e confusa. Quando ocorre o encontro entre os normais e os estigmatizados, ainda segundo Goffman (1982), os dois lados enfrentarão as causas e os efeitos do estigma.

Nessa linha goffmaniana, Marins (2017) demonstra o sentimento de mal-estar vivido por beneficiários do PBF no cotidiano da interação com os agentes públicos. A autora esclarece que esse sentimento, 
muitas vezes, resulta em estratégia de encobrimento da situação de beneficiário. Ao analisar como os grupos percebem as interações dos beneficiários, a autora observa que, “no ambiente escolar, muitas beneficiárias (mães de alunos) escondem sua posição de assistida em razão do sentimento de vergonha por receber um auxílio do Estado".

A pesquisa de Kawauchi (2019) buscou analisar as percepções de não beneficiários sobre o PBF e evidenciou que o senso comum atribui quatro efeitos negativos da política no comportamento dos beneficiários: o efeito cegonha (aumento intencional da natalidade, para aumentar o valor do benefício), o efeito preguiça (acomodação e não busca por trabalho), o efeito cachaça (uso indevido do benefício para aquisição de álcool e outras drogas); e o efeito eleição (beneficiários seriam venais ou oportunistas na hora de votar). Contudo, a pesquisadora concluiu que as percepções de não beneficiários sobre os outros efeitos encontram-se ancoradas em prejulgamentos e preconceitos que estigmatizam beneficiários e interferem nas relações sociais. O efeito encontrado por sua pesquisa foi o preconceito em relação aos beneficiários do programa.

Assim, a perspectiva de análise de implementação do PBF abordada nesse artigo lança luz sobre a pobreza a partir do controle moral, do estigma e dos julgamentos. Com base nas evidências de Lipsky (1980); Maynard-Moody e Musheno (2003); Goffman (1982); Marins (2017), a aplicação de regras e procedimentos formais de políticas, programas e serviços também passa a ser medida por julgamentos normativos e classificações identitárias que os agentes de ponta constroem sobre o público atendido.

\section{Percepções e práticas estigmatizantes das burocratas de nível de rua}

Essa seção analisa, por meio das entrevistas realizadas, as percepções e práticas que as trabalhadoras de nível de rua têm sobre o PBF. Ainda que Sistema Único de Assistência Social (SUAS) (Cardoso Jr. e Jaccoud 2009; Bichir, 2016) preconize a existência de equipamentos 
públicos que ofertem serviços assistenciais à população no nível local, para as profissionais da educação entrevistadas, a escola pública tem uma história cultural de identificar demandas dos cidadãos que ali estão. Os alunos chegam à escola com demandas que as fazem requerer atendimento especializado de outras áreas que não exatamente pedagógica, assim como muitas mães e pais ainda chegam à escola com demandas sociais e em situação de vulnerabilidade.

Para Algebaile (2009), a escola é uma instituição que, há décadas, está vinculada ao atendimento das demandas da população. É um dos vínculos mais próximos entre os cidadãos e o Estado, enquanto a assistência social, como reconhecimento de direito, tem pouco mais de 30 anos e sua presença nos territórios vêm do início dos anos 2000. Talvez por isso a população ainda desconheça a presença de um CRAS próximo a ela, ignorando o que se faz e o que esse equipamento público oferece (CARDOSO JR. e JACCOUD, 2009; BICHIR, 2016).

Para Cardoso Jr. e Jaccoud (2009), a Assistência Social no Brasil ainda é vinculada à vergonha, moralidade e julgamentos. Os serviços e programas ofertados não são vistos como direito, mas como uma ajuda. As entrevistas revelam que o PBF tem para as agentes implementadoras um sentido de "ajuda", importante para o alivio da fome em muitas famílias. Tal percepção converge com a pesquisa de Auyero (2011), quando o autor afırma que os sujeitos atendidos pelos programas sociais não são compreendidos como cidadãos, mas pacientes do Estado. Para o autor, o imaginário de ser uma ajuda faz com que os beneficiários precisem provar que são "merecedores" da "ajuda" do Estado. Essa visão cultural molda os beneficiários e interfere na interação agente-cidadão, uma vez que a "ajuda" é para quem merecer, moldando hábitos e comportamentos. Forjar o PBF como uma ajuda torna os beneficiários subjetivamente submissos ao controle do Estado.

Esses apontamentos convergem com a discussão feita por Marins (2017), quando a autora afirma que, se o PBF fosse compreendido pelos beneficiários como um direito social, o programa poderia, em al- 
guma medida, suavizar os efeitos de inferiorização e estigmatização por eles vividos. Segundo a autora, o fato de a maior parte dos beneficiários perceberem o programa como ajuda e não como um direito social pode trazer mais complicações quando se pensa na noção de autonomia e democracia.

A percepção de ajuda no processo de implementação pode ser um fator determinante no uso da discricionariedade. De acordo com Maynard-Moody e Musheno (2003), que desenvolveram a teoria da narrativa cidadão-agente, que tem como foco os cidadãos, o que de fato importa é o que ocorre na interação cotidiana entre os cidadãos e os agentes - os burocratas de rua.

Segundo os autores, os agentes da linha de frente estabelecem primeiro as identidades dos usuários e fazem julgamentos sobre quem são os "merecedores". Assim, a tomada de decisões, os aspectos identitários, a rotina, as ideias, os valores, as crenças, entre outras dimensões que, muitas vezes, podem até mesmo contrariar as decisões tomadas em níveis superiores, têm como ponto central aspectos morais dos implementadores locais. Tais elementos embasam a defınição daqueles usuários que são, ou não, merecedores dos serviços, ou de que tipo de serviços são merecedores.

O desconhecimento sobre o programa também é apontado pelas entrevistadas como sendo um fator que faz com que as pessoas não procurem pelo programa; visto que muitas pessoas não sabem aonde devem ir para requerer o benefício, a quem o PBF visa atender, e quais os objetivos do programa. Então, é possível discorrer que, embora o PBF seja muito estudado por diversas áreas do conhecimento, o senso comum, ou seja, as ideias, as crenças e os valores culturalmente construídos na sociedade sobre o programa ainda fazem com que muitas pessoas tenham vergonha de requerer o benefício, outras sejam julgadas por seu comportamento enquanto beneficiária titular do programa, reforçando o estigma que posiciona e condiciona o indivíduo à sua posição social (COFFMAN, 1982). 
Ao analisar as entrevistas, é possível captar algumas dinâmicas relacionais entre as burocratas de nível de rua e suas percepções sobre os beneficiários, alunos e mães, que constituem o principal cidadão-usuário da política. Durante as entrevistas, as implementadoras deixaram claro que suas percepções eram sobre famílias e mães, pouco falaram sobre os alunos, mesmo quando as perguntas eram sobre suas percepções em relação a eles. A visão que têm sobre os alunos é generalizada e diz respeito a fatores como "famílias desestruturadas, pais que não são participativos na escola, crianças que não gostam de ir para a escola e o fato de o público da escola ser pobre e o território ser vulnerável".

De modo geral, a percepção que as trabalhadoras da escola têm é sobre os pobres e não sobre os beneficiários alunos. Interessante notar que, quando se referem às famílias e as mães, o julgamento já existe, baseado em preconceitos sobre os beneficiários e sobre o programa, sobre como se usa o dinheiro e sobre como é o arranjo familiar.

Pelas entrevistas, cabe destacar que a mulher tem uma forte responsabilização para com os filhos, fruto de uma cultura sexista em que o papel da mulher na sociedade é cuidar dos filhos, trabalho invisibilizado pela sociedade e que tem uma importância ímpar para a produção e reprodução de mão de obra. Segundo Bartholo, Passos e Fontoura (2019); Auyero (2011), esse papel é reproduzido pelo Estado, que divide sua responsabilidade pelas famílias vulneráveis com as mulheres, tornando-as responsáveis pela gestão cotidiana do benefício. Em outras palavras, ainda que o PBF tenha um papel importante no empoderamento das mulheres, ao mesmo tempo reproduz o papel de cuidadora da família. Assim, há um julgamento na sociedade e que se espelha também nas ideias, percepções, crenças e valores das agentes implementadores de que a mulher deve gastar o dinheiro com os filhos e com a casa. Suas necessidades, ainda que seja a compra de um batom ou um perfume, acabam sendo consideradas como um gasto "errado" do benefício. 
Sobre isso, Cohn (2012) traz uma reflexão pertinente. Em seu livro, a autora relata que uma mulher havia dito, em um depoimento sobre o programa, que, com dois reais que sobraram depois de fazer as compras do mercado, ela pode comprar um batom, coisa que há muito tempo era seu desejo. E isso era uma grande felicidade para a mulher em função de sua autoestima.

Cohn (2012) pondera que a mulher tinha consciência de que, para a opinião pública, não havia nada mais condenável do que esse "gasto". Para muitos, "essa dimensão da autoestima, que para nós era inquestionavelmente intrínseca à cidadania e, por extensão, à democracia, é absolutamente invisível, ou mesmo inexistente" (COHN, 2012, p. 17). Ao perguntar às implementadoras o que elas analisam que pode melhorar no PBF, Fernanda, a secretária escolar entrevistada, disse o seguinte:

[...] a questão do gasto do dinheiro: vai gastar esse dinheiro com o quê? Porque tem muita gente que gasta realmente com a criança, mas tem gente que gasta com batom, com perfume, com um passeio... Essa questão de você ter, talvez o Bolsa-Família ser tipo um cartão de crédito, que você pode gastar só em determinados supermercados, ou determinados produtos, talvez seria interessante. Em papelarias, com determinados itens. Talvez seria interessante ter um cadastro de comércios que poderiam receber - Bolsa-Família, e que seria para aquele fim. Eu acho que isso poderia ser pensado sim, né? Uma forma de gastar, mas que o objetivo do dinheiro, que seria alimentação, educação, até saúde, um remédio que você vai comprar. Não aquele dinheiro que você recebe e você compra um sapato... ah, sapatos também são importantes, mas que isso fosse uma coisa mais direcionada. Porque a gente vê muita gente recebendo bolsa-família e fazendo festa, né, passeando e fazendo outras coisas.

É possível identificar o que Marins (2017) denomina de ética de conduta imperando sobre os beneficiários que são moralmente cobrados para serem honestos e investirem corretamente o dinheiro do benefício. Espera-se que os beneficiários sejam “boas mães”, agradecidos, 
eficazes, "bons alunos", tirem boas notas, acompanhem a educação dos filhos, sejam participativos, entre outras práticas. Conforme aponta Auyero (2011), o benefício do Estado também tem como objetivo governar os corpos e almas, moldar os hábitos, comportamentos ou as disposições daqueles que dependem de um benefício governamental. A assistente social entrevistada reforça essa tese, conforme o excerto:

No CRAS, eu já vi com o próprio funcionário, 'vai trabalhar para que? Recebe 800 reais de BF.' 'Nossa! Fulano recebeu $13^{\circ}$ e pegou o dinheiro e fez piso na casa! Por que não comprou o material escolar'? Eu acho que a família tem o direito de gastar com o que ela acha que deve. Se eu acho que estou precisando, é uma chance que tenho de pôr piso na minha casa, é o meu sonho de pôr piso ali na minha cozinha, vai dar um conforto. Na verdade, não foi na cozinha, foi no quarto da filha que teve um neném. Como a gente teve o Pedal Solidário, projeto dos ciclistas que arrecadaram material escolar, como tinha disponibilidade do material, essa família requereu e houve esse comentário, 'Nossa! Para que vem aqui pedir material escolar? Ganha 700, 800 reais de BF! Eu acho que é muito preconceituoso isso (Assistente Social).

Tal fala converge com a análise de Marins (2017). Segundo a autora, existe um controle formal do programa por meio das condicionalidades (visita domiciliar e cadastro) e informal, associado à rotina de trabalho das implementadoras locais, aos controles da vizinhança ou da sociedade de modo geral em relação aos beneficiários. A assistente social declara ouvir de outros trabalhadores do CRAS situações que ela considera preconceituosa por meio de avaliação do que Marins (2017) classifica como beneficiária "merecedora" ou "aproveitadora” a depender de como usa o benefício.

Segundo Oliveira e Daroit (2020), pela norma da política, as condicionalidades do PBF fazem com que uma rede de serviços seja acionada tanto por quem implementa a política na ponta, quanto pelos beneficiários, que devem cumprir as condicionalidades na área da saúde e educação para receberem o benefício. Ao perguntar para as implemen- 
tadoras sobre as condicionalidades do programa, se as conhecem e se sabem quais são essas condições, a assistente social teve uma resposta mais completa sobre elas. As demais implementadoras da educação demonstraram pouco conhecimento sobre esses fatores da política. As trabalhadoras da educação declararam não conhecer, ou conhecer pouco sobre as condicionalidades. O que sabiam é o que está circunscrito aos documentos oficiais sobre o PBF: os beneficiários devem ter uma frequência de $85 \%$ para crianças e $75 \%$ para adolescentes.

A partir das entrevistas com as profissionais da educação, pode-se constatar que, no entendimento das implementadoras, a condicionalidade da frequência escolar é insuficiente e que o acompanhamento dos pais nas atividades desenvolvidas pelos filhos deveria ser mais uma condição para receber o benefício. Em diversos relatos é observado que, na perspectiva dessas implementadoras, o acompanhamento dos pais é bastante deficitário. Nas percepções sobre os beneficiários (mães, alunos e famílias), observou-se que predomina uma visão dos beneficiários como "usuários não cooperativos".

No caso dessa pesquisa, a visão é mais sobre o papel dos pais na participação da vida escolar dos filhos do que necessariamente sobre os alunos beneficiários - sujeitos que as implementadoras da escola dizem não saber quem são - no sentido de que não colaboram com o serviço que os burocratas de nível de rua precisam prestar, isto é, o ensino. Joana, a diretora da escola analisada, relata que procura o CRAS quando identifica demandas que não são diretamente relacionadas à frequência dos alunos; para auxiliar uma família que precisa se cadastrar no PBF; para relatar o caso de uma mãe que não está usando o dinheiro do benefício para comprar coisas que ela considera o certo; e para denunciar casos de famílias que, na sua percepção, não merecia estar no programa porque não gastam o benefício com o filho, mas sim com uso de drogas e com bebidas alcóolicas.

Há, portanto, diferenças nas percepções entre as implementadoras que atuam na escola e as que atuam no CRAS. O PBF (e outras políticas sociais) exige das implementadoras da escola um repertório de saberes 
e de práticas que, muitas vezes, não são por elas reconhecidos pois o programa, ainda que tenha condicionalidades educacionais, é uma política social. Assim, os saberes e práticas mobilizados pelo PBF estão, em grande medida, vinculados a outras perspectivas que não as pedagógicas, o que têm induzido novos e outros deslocamentos dos profıssionais que atuam na escola pública, especialmente após a universalização do acesso à educação básica, a partir de meados dos anos 1990.

Os profıssionais da assistência social, por sua vez, têm formação para atuar com famílias em situações de vulnerabilidade social. Nesse sentido, o CRAS cumpre um papel estratégico nos territórios, uma vez que as equipes socioassistenciais acompanham as famílias referenciadas no Cadastro Único e mobilizam outros profıssionais que atuam no nível local. Em outras palavras, diferentemente das escolas e de seus profissionais, assistentes sociais e os CRAS atuam em rede e, por isso, podem articular essas interações no nível local, conforme afirmam Oliveira e Daroit (2020).

Desse modo, a condicionalidade educacional potencializa a presença do aluno beneficiário na escola e, por esse meio, articula e induz outras interações entre os demais atores vinculados ao PBF (trabalhadores da educação, mães, responsáveis, trabalhadores da assistência social e da saúde, dentre outros). Por meio desse vetor, as interações cotidianas nas linhas de frente do serviço público acionam outros serviços quando a demanda é identificada. Ainda que formalmente o CRAS e a escola analisados tenham uma interação fraca, os efeitos cotidianos e informais atrelados à condicionalidade são fortes.

\section{Considerações finais}

Segundo Cohn (2012), as condicionalidades do PBF sempre tiveram posição de destaque na concepção do desenho, no sentido de constituírem traçadores fundamentais para as políticas públicas relacionadas a elas, mas também às demais. Para o autor, o PBF é um programa transversal que articula as demais políticas sociais no país. 
A introdução das condicionalidades associa-se ao fato de constituírem instrumentos de monitoramento das políticas locais pelos próprios gestores, e não uma estratégia para controlar os beneficiários. A ideia das condicionalidades pressupõe acesso aos equipamentos públicos essenciais a toda a população, sobretudo à de baixa renda. Elas não têm - ou não deveriam ter - um caráter disciplinador ou punitivo junto aos beneficiários e sua concepção diz respeito ao acompanhamento das próprias políticas.

As evidências dessa pesquisa revelam, entretanto, que as condicionalidades têm efeitos cruzados, que se entrelaçam: ao mesmo tempo que produzem efeitos positivos e desejáveis, também geram efeitos simbólicos colaterais e perversos, materializados por meio na interiorização de classificações estigmatizantes (como "famílias desestruturadas", boas ou más mães), preconceitos e julgamentos.

Nessa direção, a partir das contribuições de Maynard-Moody e Musheno (2003), as decisões das burocratas de nível de rua são tomadas com base na interpretação e tradução das normas definidas para o PBF e, também, com base em critérios subjetivos: o perfil dos beneficiários e as percepções que esses agentes têm em relação a esses sujeitos - os destinatários do programa. É nesse entrelaçamento que os julgamentos morais e as práticas estigmatizantes podem emergir. A centralidade de suas atuações parte da norma que regula a ação e o trabalho das implementadoras, mas o cotidiano, a discricionariedade e a compreensão moral e subjetiva que têm do outro moldam o resultado da política para maior ou menor inclusão.

A norma, portanto, deixa de ser um balizador central para se tornar uma variável relativa, já que, segundo Lipsky (1980) e Goffman (1982), as experiências acumuladas no exercício do trabalho cotidiano desempenhado pelos agentes que atuam na ponta, associadas às percepções e subjetividades que se conformam sobre os cidadãos atendidos nos processos de interação moldarão as práticas de implementação.

Por trás de um aparente avanço com relação às políticas de combate à pobreza, o preconceito que estigmatiza beneficiários entre merecedor, 
ou não, está presente na implementação e configura-se como efeito não revelado - efeito perverso da implementação. Produz-se um efeito não reconhecido, não debatido, e que é um contraponto ao reconhecimento desses beneficiários como portadores de direitos. Tais efeitos se configuram como um entrave ao exercício da cidadania.

Sobre a condicionalidade educacional, pode-se inferir que, em certa medida, no entendimento das implementadoras, o PBF está relacionado primeiramente à assistência social. A educação é uma dimensão secundária. É possível afirmar que os profissionais da escola pouco participam da formulação do programa, uma vez que não recebem cursos, formações e/ou aperfeiçoamentos. Observou-se que as implementadoras da escola não participam de reuniões e decisões em nível local, no qual cada equipamento público executa o que a norma oficial delega.

Essas dinâmicas podem (re)produzir percepções preconceituosas, ancoradas na tutela e na ótica do favor, distantes da noção de direitos de cidadania. As entrevistas revelam que uma das maiores preocupações que os implementadores têm é com a alocação dos recursos: como o dinheiro é gasto. Nesse sentido, para as profissionais do espaço escolar, se as mães não reverterem os recursos para os alunos, comprando materiais escolares, roupas, sapatos, cuidados com a casa, entre outros, e utilizarem o dinheiro para outros fins, elas devem ser retiradas do programa.

Com isso, as questões de vulnerabilidade em que estas famílias se encontram deixam de ser discutidas a fundo, dando lugar a práticas que produzem preconceitos, julgamentos, estigmatizam e moldam os hábitos e comportamentos dos beneficiários, pautados a partir do que se ouve dizer. A implementação do PBF - e de outras políticas - revela essas tensões e os dilemas que decorrem dessas dinâmicas, especialmente quando tratam da efetivação de direitos, da inclusão e do fortalecimento da cidadania.

\section{Referências}

ALGEBAILE, E. Escola pública e pobreza no Brasil: a ampliação para menos. Rio de Janeiro: Lamparina, Faperj, 2009. 
AUYERO, J. Patients of the state: An Ethnographic Account of Poor People's Waiting. Latin American Research Review, vol. 46, n. 1, 2011.

BARTHOLO, L.; PASSOS, L. FONTOURA, N. Bolsa Família, autonomia feminina e equidade de gênero: o que indicam as pesquisas nacionais? Cadernos Pagu [online]. 2019, n. 55: e195525.

BICHIR, R. M. Novas agendas, novos desafios: reflexões sobre as relações entre transferência de renda e assistência social no Brasil. Novos Estudos CEBRAP, ed. 104, 35, (1), 111-136, 2016.

BRASIL. Lei ordinária $n^{\circ} 10.836$, de 9 de janeiro de 2004. Cria o Programa Bolsa Família e dá outras providências. Disponível em: < http://www.planalto.gov.br/ ccivil_03/_ato2004-2006/2004/lei/l10.836.htm>. Acesso em: 15 nov. 2020.

BRASIL. Ministério da Cidadania. Informe Bolsa e Cadastro $n^{\circ} 783$. Brasília: Ministério da Cidadania, 2021. Disponível em: http://www.mds.gov.br/webarquivos/sala_de_imprensa/boletins/boletim_bolsa_familia/2021/abril/ Boletim_BFInforma783.html. Acesso em: 22 jun. 2021.

CARDOSO JR, J. C.; JACCOUD, L. Políticas Sociais no Brasil: Organização, Abrangência e Tensões da Ação Estatal. In.: JACCOUD, L. (org.). Questão Social e Políticas Sociais no Brasil Contemporâneo. Brasília: IPEA, 2009.

COHN, A. Cartas ao presidente Lula: Bolsa Família e direitos sociais. Rio de Janeiro: Pensamento Brasileiro, 2012.

GOFFMAN, E. Estigma: notas sobre a manipulação da identidade deteriorada. $4^{\mathrm{a}}$ ed. Rio de Janeiro: Zahar Editores S. A., 1982.

KAWAUCHI, M. O programa Bolsa Família e percepções de não beneficiários: um estudo sobre o efeito preconceito. 2019. 204 f. Tese (Doutorado Desenvolvimento, Sociedade e Cooperação Internacional) - Universidade de Brasília, Brasília, 2019.

LIPSKY, M. Street level bureaucracy: dilemmas of the individual in public services. New York: Russell Sage Foundation, 1980.

MAYNARD-MOODY, S.; MUSHENO, M. Cops, teachers, counselors: narratives of street-level judgment. Ann Arbor, United States: University of Michigan Press, 2003.

MARINS, M. T. A. Bolsa Família: questões de gênero e moralidades. Rio de Janeiro: Editora UFRJ; Faperj, 2017.

MEYERS, M.; VORSANGER, S. Burocratas de nível de rua e a implementação de políticas públicas. In: PETERS, G.; PIERRE, J. Administração Pública Contemporânea. São Paulo: Editora UNESP, 2013. 
OLIVEIRA, B. R. A implementação do Programa Bolsa Família sob a perspectiva da condicionalidade educacional: uma análise a partir dos agentes públicos de base. Revista do Serviço Público, Brasília, v. 65, n. 4, 517-544, out./dez. 2014.

OLIVEIRA, B. R.; PEIXOTO, M. C. L. Trazendo à tona aspectos invisíveis no processo de implementação de políticas públicas: uma análise a partir do Programa Oportunidades. In: PIRES, R. R. C (org.). Implementando desigualdades: reprodução de desigualdades na implementação de políticas públicas. Rio de Janeiro: Ipea, 2019.

OLIVEIRA, B. R.; DAROIT, D. Public Policy Networks and the Implementation of the Bolsa-Família Program: An Analysis Based on the Monitoring of School Attendance. Education Policy Analysis Archives, 28(120), 2-27, 2020. Disponível em: https://doi.org/10.14507/epaa.28.4499.

PIRES, R. R. C. (org.). Implementando desigualdades: reprodução de desigualdades na implementação de políticas públicas. Rio de Janeiro: Ipea, 2019.

PIRES, R. R. C.; LOTTA, G. Burocracia de nível de rua e (re)produção de desigualdades sociais: comparando perspectivas de análise. In.: PIRES, R. R. C (org.). Implementando desigualdades: reprodução de desigualdades na implementação de políticas públicas. Rio de Janeiro: Ipea, 2019.

SILVA, M. O. S.; YAZBEK, M. C.; DI GIOVANNI, G. A Política Social Brasileira no Século XXI: a prevalência dos programas de transferência de renda. $6^{\text {a }}$ ed. rev. e atual. São Paulo: Cortez, 2012.

WINTER, S. Perspectivas de implementação: status e reconsideração. In: PETERS, G. \& PIERRE, J. Administração Pública Contemporânea. São Paulo: Editora UNESP, 2013.

\section{Notas}

1 Mestre em Educação pela Universidade Federal de Ouro Preto (UFOP), Ouro Preto - MG - Brasil. ORCID: https://orcid.org/0000-0002-7963-7826. E-mail: marisassufop@gmail.com.

2 Professor dos Programas de Pós-Graduação em Educação e Economia Aplicada da Universidade Federal de Ouro Preto (UFOP), Ouro Preto - MC - Brasil. ORCID: https://orcid.org/0000-0003-0956-4753. E-mail: breynner@ufop.edu.br.

3 A pesquisa obedeceu a todos os protocolos exigidos pelo Comitê de Ética em Pesquisa da instituição (Parecer n ${ }^{\circ}$ 4.046.727/CAAE: 25806119.4.0000.5150). O sigilo, o anonimato e a confidencialidade dos dados coletados foram assegurados. Todos os nomes das entrevistadas foram trocados como forma de preservar suas identidades. 